УДК $316: 323.21$

$10.17213 / 2075-2067-2020-4-127-139$

\title{
ОБЩЕСТВЕННАЯ СОСТОЯТЕЛЬНОСТЬ \\ ИНСТИТУТА СИТИ-МЕНЕДЖМЕНТА В ОЦЕНКАХ НАСЕЛЕНИЯ \\ РОСТОВСКОЙ ОБЛАСТИ И РЕСПУБЛИКИ АДЫГЕЯ
}

\author{
(C) 2020 г. А. В. Дятлов, В. В. Ковалев
}

\section{Южный федеральный университет, г. Ростов-на-Дону, Россия}

Целью исследования выступает выявление общественной состоятельности сити-менеджмента в оценках получателей муниципальных услуг Ростовской области и Республики Адыгея на основе сформулированных авторами эмпирических индикаторов.

Методологическая база исследования основывается на положениях неоинституцииональной теории Д. Норта, применяемых к изучению процессов институционализации сити-менеджмента в системе муниципального управления, а в конкретно-прикладном аспекте - массовом социологическом опросе, проведенном в муниципальных образованиях Ростовской области и Республики Адыгея.

Результаты исследования. Осуществлена интерпретащия результатов массового сочиологического опроса, проведенного среди населения муниципальных образований Ростовской области и Республики Адыгея на предмет определения общественной состоятельности института сити-менеджмента. Под общественной состоятельностью понимается достижение основных иелей, поставленных перед институтом сити-менеджмента, прежде всего, привлечение профессиональных управленцев для улучшения показателей социально-экономического развития территорий. В качестве критериев для оченки сформулированы четыре аспекта: доверие к реформе, иели реформы, удовлетворенность реформой и ожидание последствий от реформы. Авторы пришли к выводу, что значительная масса населения реформе не доверяет, видит в ней иные цели, чем декларирует законодатель, не удовлетворена результатами, опасается наступления негативных последствий от её реализации. В то же время имеются и иные результаты от введения сити-менеджмента, поскольку выделены устойчивые группы респондентов, высказавшие положительное к ней отношение, что последовательно проявляется по всем аспектам оценки, включая отказ от значимости института избираемых мэров.

Перспективы дальнейших исследований авторы видят в проведении фокусированных интервью с бизнес-сообществами и гражданскими активистами, которые позволят расширить субъектную базу измерения общественной состоятельности института сити-менеджмента в муниципальном управлении.

Ключевые слова: институт сити-менеджмента; общественная состоятельность; сити-менеджер; глава муниципального образования; местное самоуправление; муниципальное сообщество; социально-экономическое развитие; Ростовская область; Республика Aдыгея. 


\title{
PUBLIC SOLVENCY OF THE INSTITUTE OF CITY MANAGEMENT IN THE ESTIMATES OF THE POPULATION OF THE ROSTOV REGION AND THE REPUBLIC OF ADYGEA
}

\author{
(C) 2020 A.V. Dyatlov, V. V. Kovalev
}

\section{Southern Federal University, Rostov-on-Don, Russia}

The purpose of the study is to identify the social viability of city management in the estimates of recipients of municipal services in the Rostov region and the Republic of Adygea based on the authors' empirical indicators.

The methodological basis of the research is based on the provisions of the neoinstitutional theory of D. North, applied to the study of the processes of institutionalization of city management in the system of municipal management, and in a specific applied aspect-a mass sociological survey conducted in the municipalities of the Rostov region and the Republic of Adygea.

Research result. The results of a mass sociological survey conducted among the population of municipalities of the Rostov region and the Republic of Adygea were interpreted to determine the social viability of the Institute of city management. Social solvency refers to the achievement of the main goals set for the Institute of city management, first of all, the involvement of professional managers to improve the indicators of socio-economic development of territories. Four aspects are defined as criteria for evaluation: confidence in the reform, goals of the reform, satisfaction with the reform, and expectation of the consequences of the reform. The authors came to the conclusion that a significant mass of the population does not trust the reform, sees in it other goals than the legislator declares, is not satisfied with the results, and fears the onset of negative consequences from its implementation. At the same time, there are other results from the introduction of city management, since there are stable groups of respondents who expressed a positive attitude to it, which is consistently shown in all aspects of the assessment, including the rejection of the significance of the institution of elected mayors.

The authors see prospects for further research in conducting focused interviews with business communities and civil society activists, which will expand the subject base for measuring the social viability of the Institute of city management in municipal administration.

Key words: institute of city management; public solvency; city manager; head of the municipality; local government; municipal community; socio-economic development; Rostov region; Republic of Adygea.

Введение. Формально создание института сити-менеджмента изменило лишь институциональный порядок легитимации процедуры вступления в должность руководителя муниципального образования: от избрания через механизм муниципальных выборов к избранию конкурсной комиссией. Однако эти формальные изменения на практике привели к качественным трансформациям самих принципов работы глав муниципалитетов. Новым стал «заказчик», оценивающий качество получения муниципальных услуг. Это городская Дума и губернатор, формирующие состав комиссии. Серьезное обновление должен претерпеть и сам глава муниципалитета. Новый порядок конкурсного назначения предполагает, что руководитель муниципального образования в формирующихся институциональных условиях выступает эффективным менеджером, основная сфера деятельности которого - социально-экономическая. Теперь он хозяйственник, отвечающий за то, чтобы вверенное ему муниципальное образование выходило на новый уровень воспроизводства 
отчетных нормативных показателей, выступающих индикатором его эффективной деятельности на посту главы муниципалитета.

С учетом сказанного целью исследования выступает выявление общественной состоятельности сити-менеджмента в оценках получателей муниципальных услуг Ростовской области и республики Адыгея на основе сформулированных авторами эмпирических индикаторов.

\section{Социологический инструментарий.} Нами было опрошено 1152 респондента, проживающих в городах Ростов-на-Дону, Майкоп, Адыгейск, Таганрог, Батайск, Каменск-Шахтинский, а также в нескольких муниципальных поселениях Семикаракорского района. Для отбора респондентов применялись такие критерии, как пол, возраст, социальный статус, место жительства. Репрезентативность выборки обеспечивалась на основе принципа пропорционального соответствия. Ведущий критерий отбора респондентов - место жительства.

Прежде чем мы представим результаты, дадим несколько пояснений относительно методики их оценки.

В виде базового нами используется понятие «общественная состоятельность». Под ним понимается достижение основных целей, поставленных перед институтом ситименеджмента. Прежде всего, это привлечение профессиональных управленцев для улучшения показателей социально-экономического развития территорий. Соответственно, состоятельным сити-менеджмент может быть признан лишь в том случае, если по итогам деятельности городских управляющих будут улучшены социально-экономические показатели развития территорий, где применялась новая управленческая модель. Критериями общественной состоятельности выступают две позиции:

- отсутствие массовых проявлений недовольства со стороны населения вследствие его исключения из политического процесса в качестве электората по выборам глав муниципальных образований;

- реальное улучшение показателей социально-экономического развития территорий после введения института сити-менеджмента.

В означенных выше муниципальных образованиях не только создана правовая платформа для реализации в управленческую практику института сити-менеджмента, но и имеется опыт функционирования данной модели в течение нескольких лет. В связи с этим респонденты, которым было предложено принять участие в опросе, оценивают именно свой опыт взаимодействия с сити-менеджерами, выражают собственные представления о том, как понимается данный институт и чего от него следует ожидать. Вся совокупность вопросов анкеты может быть разбита на четыре блока: 1) есть ли доверие к реформе; 2) в каких целях она проводится; 3) удовлетворены ли результатами реформы; 4) следует ли ожидать от неё негативных последствий («цена реформы»).

Результаты исследования. Итак, начнем с первого блока, с вопросов о доверии.

В Ростовской области и Адыгее положительно восприняли отмену выборов около трети опрошенных. Практически столько же отнеслись к реформе отрицательно - 36,8\%

Таблица 1

Как Вы оцениваете замену главы муниципального образования, избираемого населением на выборах, на руководителя, работающего по контракту, в \%?

\begin{tabular}{|l|c|}
\hline \multicolumn{1}{|c|}{ Параметры оценки } & Результат \\
\hline Однозначно негативно, мэра нужно выбирать из числа претендентов & 13,7 \\
\hline Скорее негативно, чем позитивно & 23,1 \\
\hline Нейтрально (для меня эта замена ничего не значит) & 30 \\
\hline Преимущественно положительно & 21,9 \\
\hline $\begin{array}{l}\text { Однозначно положительно, контрактника легче проверять и, если что, } \\
\text { увольнять или привлекать к ответственности }\end{array}$ & 11,3 \\
\hline
\end{tabular}


и чуть меньше трети - 30\% нейтрально. Как видно, мнения разделились примерно поровну.

Полученные результаты, зафиксированные в табл. 1, комментировать вне контекста других вопросов крайне сложно, поэтому на данном этапе мы только констатируем равенство мнений по трем позициям, чтобы в дальнейшем уточнить их через более информативные вопросы.

Полученные результаты в основе своей вполне совпадают с теми, которые представлены в табл. 1, что свидетельствует о наличии неких устойчивых групп, позиции которых содержательно не колеблются под влиянием переформулированных вопросов, имеющих, кроме прочего, контрольное значение. Мы имеем три группы, голоса между которыми разделились примерно поровну. Одна группа ориентирована на признание ценностей демократии; вторая настроена негативно на тот вариант выборов, который сложился в России, имея в виду его формально-имитационный характер; третья - индифферентна к любым устойчивым институциям, предпо- читая конкретные социально-экономические результаты вне оценки правовых и политических условий их достижения. Мы считаем, что вторая группа состоит из социальных акторов, разочарованных конкретно российской практикой выборов, а не демократией вообще. В связи с этим её можно рассматривать в качестве резервной как для «сторонников демократии» $(30,0 \%)$, так и для «равнодушных к ней» $(34,8 \%$ ).

Выводы по первому блоку. В Ростовской области и Республике Адыгея недоверие к реформе преобладает. Есть группа активных противников отмены выборов, есть сомневающиеся или равнодушные на почве снижения интереса к демократии, последних несколько больше, но выявлена также группа активных сторонников института сити-менеджмента, с которым связывают надежды на повышение профессионализма в системе муниципального управления. Уточнение представленной позиции предполагает необходимость оценки мнения респондентов по ряду других вопросов, объединенных нами во второй, третий и четвертый блоки.

Таблица 2

Сити-менеджмент появился как вариант, сменивший практику избрания главы муниципального образования. Не является ли это свидетельством отказа от принципов демократии, в \%?

\begin{tabular}{|l|c|}
\hline \multicolumn{1}{|c|}{ Параметры оценки } & Результат \\
\hline Да, демократии без выборов не бывает, сами выбираем, сами и отвечаем & 30 \\
\hline $\begin{array}{l}\text { Нет, поскольку выборы давно превратились в формальный механизм манипу- } \\
\text { лирования сознанием избирателей }\end{array}$ & 34,9 \\
\hline $\begin{array}{l}\text { Выборы или назначение по конкурсу не имеют значения, если позволяют ре- } \\
\text { шать основные проблемы социально-экономического развития территорий }\end{array}$ & 34,8 \\
\hline
\end{tabular}

Таблица 3

Как Вы считаете, какая главная цель преследовалась при замене выборов мэра процедурой конкурсного отбора, в \%?

\begin{tabular}{|l|c|}
\hline \multicolumn{1}{|c|}{ Параметры оценки } & Результат \\
\hline Экономическая (улучшить хозяйственное развитие территорий) & 20,1 \\
\hline Политическая (достроить властную вертикаль) & 21,5 \\
\hline Повысить профессионализм муниципальных руководителей & 21,8 \\
\hline Никаких особых целей не было (реформа ради реформы) & 27,2 \\
\hline Затрудняюсь ответить & 2,6 \\
\hline
\end{tabular}


Блок №2 - цели реформы.

Через данный вопрос у нас есть возможность определить, насколько точно целевые представления о реформе у Правительства соответствует ожиданиям от нее, выявленным в сознании респондентов. Первая и третья строки таблицы отражают соответственно цель реформы (улучшить хозяйственное развитие территорий через повышение социально-экономических показателей) - 20,1\% и способ её достижения (повысить профессионализм муниципальных руководителей) - 21,8\%. По совокупности мы получаем практически $42 \%$ из числа опрошенных, чьи представления не расходятся с декларированными целями реформы со стороны её инициаторов. Показательно, что количество убежденных в том, что реформа проводилась для достройки политической пирамиды на низовом, муниципальном, уровне, не столь уж и велико - всего 21,5\%, но особенно это значимо, если сравнивать с позицией ученого сообщества, среди которого точка зрения о том, что сити-менеджмент институциализируется приоритетно для достижения политических целей, является доминирующей [1, $2,3,4]$. Впрочем, согласованность представлений респондентов с правительственными декларациями ещё не свидетельствует об успешности самой реформы. К этому аспекту мы ещё вернемся.

Далее определимся с тем, есть ли у новой модели муниципального управления необходимый потенциал для достижения цели. Таковым следует считать наличие соответствующих профессиональных качеств у ситименеджеров. Напомним, что сама реформа порядка вступления в должность, по замыслу реформаторов, инициировалась именно для того, чтобы обеспечивать приход к власти не «уличных политиков», а специально под- готовленных управленцев, или, если искать аналогии на Западе, руководителей, имеющих связи с бизнесом.

Возможности у действующих сити-менеджеров достигнуть провозглашенные реформой цели увидели только 28,2\% из числа опрошенных. Это даже меньше уже выделенной группы, состоящей из трети от общего массива выборки, состав которой можно считать активными сторонниками конкурсного порядка назначения руководителей муниципальных образований. Подобный расклад свидетельствует о том, что группа сторонников реформы может начать размываться из-за возможных неудач в достижении продекларированных целей. Чуть большее количество респондентов, не увидевших у сити-менеджеров необходимого потенциала для качественной реализации реформы. Эта группа едва ли может быть монолитна по своему составу. При том или ином потенциале развития муниципальной территории она способна распадаться как на приверженцев, так и на противников принятого порядка легитимности руководителей муниципального уровня. И, наконец, самым частным оказался выбор третьего варианта - «Принцип не имеет значения, всё зависит от каждого конкретного случая» $(41,4 \%)$. Это антиинституциональная позиция, поскольку её сторонники убеждены в особой роли субъектного фактора в достижении высоких показателей социально-экономического развития территорий.

Подводя краткий промежуточный итог, связанный с оценкой целевой направленности реформы по институционализации сити-менеджмента в систему муниципального управления, следует отметить, что на уровне массовых представлений проявляется последовательная дифференциация позиций. Явно выделяются три группы респондентов.

Таблица 4

Обладают ли, по Вашему мнению, сити-менеджеры бо́льшим потенциалом для улучшения социально-экономических показателей развития территорий, чем избираемые мэры, в \%?

\begin{tabular}{|l|c|}
\hline \multicolumn{1}{|c|}{ Параметры оценки } & Результат \\
\hline Да & 28,2 \\
\hline Нет & 29,6 \\
\hline Принцип не имеет значения, всё зависит от каждого конкретного случая & 41,4 \\
\hline
\end{tabular}


Первая из них состоит из 40-45\% из числа опрошенных и ориентирована на четкую солидарность с позицией власти относительно того, что конкурсный порядок назначения на должность глав муниципальных образований принимается в целях повышения профессионализма муниципальных руководителей; вторая образуется из 35-40\% респондентов и может быть охарактеризована доминантными установками на то, что подлинными целями реформы является установление политического контроля на уровне местной власти; третья наиболее малочисленная (около 25\%), состоит из респондентов, у которых нет четкого или однозначного понимания целевой природы реформы.

Далее обратимся к вопросам из блока №3 - удовлетворенность результатами реформы.
Ожидаемо, что вариант ответа «да, качество жизни населения улучшилось» выбрало наименьшее число респондентов - 27,7\%. Правда, численность опрошенных, которые оценивают реформу, как провальную, ненамного больше - 29\%,6. Показательно при этом, что около половины всех респондентов (42,7\%) убеждены, что принятый порядок легитимации руководителя муниципального образования никак не повлиял на качество муниципального управления. Мыл видим обратную связь: достижение иелей реформы, то есть реальное улучшение жизни населения, начинает в сознании опрашиваемых влиять на то, какова у нее цеель.

Представленные в табл. 6 данные свидетельствуют о том, что, по меньшей мере, одна поговорка о бедах России, озвученная классиком про дороги, постепенно перестает

Таблица 5

Целью реформы планировалось, что ее реализация приведет к повышению качества жизни населения. Как Вы считаете, достигла ли реформа своей цели, в \%?

\begin{tabular}{|l|c|}
\hline \multicolumn{1}{|c|}{ Параметры оценки } & Результат \\
\hline Да, качество жизни населения улучшилось & 27,7 \\
\hline $\begin{array}{l}\text { Нет, сити-менеджеры показали себя безответственными и непрофессиональны- } \\
\text { ми руководителями }\end{array}$ & 29,6 \\
\hline $\begin{array}{l}\text { Смена принципов вступления в должность руководителя муниципального обра- } \\
\text { зования никак не повлияла на качество жизни населения }\end{array}$ & 42,7 \\
\hline
\end{tabular}

Оцените качество работы сити-менеджеров по трем параметрам, в \%

\begin{tabular}{|l|c|c|c|c|}
\hline \multicolumn{1}{|c|}{ Параметры оценки } & \multicolumn{3}{|c|}{ Результат } \\
\cline { 2 - 5 } & да & нет & $\begin{array}{c}\text { стало } \\
\text { только } \\
\text { хуже }\end{array}$ & $\begin{array}{c}\text { Затрудняюсь } \\
\text { ответить }\end{array}$ \\
\hline $\begin{array}{l}\text { Увеличилось ли качество автомобильных дорог в Вашем } \\
\text { городе после того, как его возглавил сити-менеджер }\end{array}$ & 32 & 41,5 & 11,9 & 14,6 \\
\hline $\begin{array}{l}\text { Увеличился ли объем строительства муниципального } \\
\text { жилья в Вашем городе после того, как его возглавил си- } \\
\text { ти-менеджер }\end{array}$ & 19,9 & 37,7 & 13,4 & 28,9 \\
\hline $\begin{array}{l}\text { Увеличилось ли качество предоставления коммунальных } \\
\text { услуг (свет, газ, вода, уборка мусора) в Вашем городе } \\
\text { после того, как его возглавил сити-менеджер }\end{array}$ & 19,6 & 42,9 & 19,4 & 18,1 \\
\hline
\end{tabular}


быть актуальной, а вот «квартирный вопрос», поднятый другим классиком, всё также обладает потенциалом негативного воздействия на общество. Тем не менее, при совокупной оценке позиций респондентов мы опять получаем в качестве наиболее часто выбираемого варианта - отсутствие любых изменений, как позитивных, так и негативных, которые можно было бы связать с деятельностью сити-менеджеров. Некоторая корректировка в результаты может быть внесена, если мы за основу коррелячии, как и предыдущих случаях, возьмем вариант ответа «заменить на муниципальном уровне политические отношения на административно-хозяйственные». Показательно, что и здесь наблюдается удельное возрастание численности респондентов, давших положительную оценку работе сити-менеджеров: 40,8\% > 32\% по строительству автомобильных дорог, 26,2 > 19,9\% - по строительству муниципального жилья, 23,6 > 19,6\% - по качеству предоставления коммунальных услуг.

В целом можно считать, что большая часть респондентов отрицательно оценила деятельность сити-менеджеров на посту руководителей муниципальных образований. Несмотря на то, что вариант «стало только хуже», как правило, избирался реже остальных (исключая качество предоставления коммунальных услуг), отсутствие результата большинством воспринимается как результат негативный. Это означает, что реформа в основе своей не достигла своей цели: или из-за отсутствия у сити-менеджеров ожидаемого уровня профессионализма, или вследствие их личной незаинтересованности в эффективном управлении, или по причине наличия институциональных барьеров, препятствующих применению их профессиональных компетенций для повышения социальноэкономических показателей развития муниципалитетов. Но для общего выввода важно принимать наличие скрытых взаимосвязей. Одной из таких является корреляция между высокой оценкой качества оказания муниципальных услуг и единообразным пониманием иелей реформы между населением и инициаторами реформы. Согласное понимание по иелям реформы между реформаторами и населением чаще всего образуется в том случае, если респондент реально ощущает повынение качества жизни, связывая его с тем, что новый порядок назначения муниципальных руководителей дает возможность инсталлировать на выстие должности в системе муниципального управления действительно настоящих профессионалов, а не безответственных политиков.

И, наконец, рассмотрим результаты по четвертому блоку вопросов, направленных на оценку общественной состоятельности института сити-менеджмента. Это вопросы о возможных рисках данной модели, иначе говоря, «цене реформы» на начальном этапе её реализации в системе муниципального управления.

Респондентам были предложено оценить вероятность наступления нескольких вариантов рисков управленческого характера либо сделать вывод о том, что возможность их проявления несущественна. Полученные результаты показали, что актуальность данных рисков считается весьма вероятной. Наибольшая опасность видится в «недоверии населения к назначаемому, а не вы-

Какие управленческие риски возникли (могут возникнуть) в результате введения модели сити-менеджмента, в \%?

Таблица 7

\begin{tabular}{|l|c|}
\hline \multicolumn{1}{|c|}{ Параметры оценки } & Результат \\
\hline Недоверие населения к назначаемому, а не выбираемому управленцу & 47,8 \\
\hline Увеличение коррупционной составляющей во властных структурах & 36,9 \\
\hline Снижение эффективности главы муниципального образования & 18,3 \\
\hline $\begin{array}{l}\text { Снижение личной ответственности главы муниципального образования перед } \\
\text { населением }\end{array}$ & 30,1 \\
\hline Оснований для возможного возникновения перечисленных выше рисков нет & 22,3 \\
\hline
\end{tabular}


бираемому управленцу» - 47,8\%. Угрозу такого развития событий видит практически половина от числа опрошенных. Данный результат одновременно может быть интерпретирован и как общее недоверие к власти. Фактически сити-менеджмент представляет собой только механизм вступления в должность, иной порядок её легитимации. Объем полномочий и юридических возможностей по управлению территориями у мэров и городских управляющих одинаковый. Новая модель предполагает возможность выбора профессионалов (сити-менеджеров) профессионалами (конкурсной комиссией). Однако это выводит процедуру назначения муниципального руководителя за пределы общественного контроля. Отсутствие доверия в этих условиях есть показатель неверия в профессиональный потенциал сити-менеджера. Это легко показать, если построить комбинированную таблицу сопряженности, сопоставив результаты по общей выбор- ке с теми, которые получены только по той группе респондентов, которая выбрала в качестве актуального варианта возможность роста недоверия у муниципального сообщества к назначаемому, а не выбираемому управленцу.

Несложно заметить, что риск недоверия к назначаемому, а не выбираемому муниципальному руководителю, переносится и на его профессиональные качества. А раз эта связь сохраняется в течение нескольких лет после институцуионализации сити-менеджмента в Ростовской области и в Республике Адыгея, значит, сити-менеджеры не сделали того необходимого минимума, который стал бы основанием для преодоления недоверия.

Предложенная респондентам формулировка ответов, как мы полагаем, отражает наиболее типичный спектр представлений о выборах, сложившихся в массовом сознании внутри современного российского социума.

Таблица 8

Обладают ли, по Вашему мнению, сити-менеджеры бо́льшим потенциалом для улучшения социально-экономических показателей развития территорий, чем избираемые мэры, в \%?

\begin{tabular}{|l|c|c|c|}
\hline \multicolumn{1}{|c|}{ Параметры оценки } & \multicolumn{2}{|c|}{ Результат } \\
\cline { 2 - 4 } & Да & Нет & $\begin{array}{c}\text { Принцип не имеет значения, } \\
\text { всё зависит от каждого } \\
\text { конкретного случая }\end{array}$ \\
\hline Вся совокупность респондентов & 28,2 & 29,6 & 41,4 \\
\hline $\begin{array}{l}\text { Респонденты, выбравшие вариант ответа } \\
\text { в табл. 9 «недоверие населения к назна- } \\
\text { чаемому, а не выбираемому управленцу» }\end{array}$ & 19,3 & 33 & 47,7 \\
\hline
\end{tabular}

Таблица 9

Насколько важен, по Вашему мнению, правовой порядок вступления в должность главы муниципального образования, в \%?

\begin{tabular}{|l|c|}
\hline \multicolumn{1}{|c|}{ Параметры оценки } & Результат \\
\hline $\begin{array}{l}\text { Отмену выборов приму только положительно, часто выборы — это отмывание } \\
\text { денег или механизм получения привилегий и неприкосновенности }\end{array}$ & 29,7 \\
\hline $\begin{array}{l}\text { Я устал от политики и приму главу муниципалитета в любом качестве, если он } \\
\text { будет успешно решать социально-экономические проблемы }\end{array}$ & 47,3 \\
\hline $\begin{array}{l}\text { Отмену выборов мэра оцениваю крайне негативно, т.к. для меня демократичес- } \\
\text { кие принципы имеют большое значение }\end{array}$ & 23 \\
\hline
\end{tabular}


Выбор по первой строке объединяет респондентов, у которых в целом негативное отношение к процедуре избрания властных органов: либо в силу консервативно-патерналистских представлений о власти, когда максимальная степень допущения избирательного процесса признается необходимой только в отношении главы государства, либо в силу разочарования в особенностях российской демократии, проявляющихся в том числе в формализации таких институтов демократии, как муниципальные выборы. Таковых по результатам исследования оказалось $29,7 \%$. По социальному составу в данной группе больше всего государственных и муниципальных служащих (43,5\%). Остальные социальные слои представлены более-менее равномерно.

Выбор по второй строке направлен на выявление социальной группы, в которой арти- кулируется в качестве ведущей направленности необходимость повышения качества социальной жизни для населения муниципалитетов. Политические ценности здесь отходят на задний план. Данная группа наиболее многочисленная - 47,3\%. В ней больший удельный вес занимают рабочие (26,5\%), предприниматели $(27,3 \%)$ и служащие в негосударственных учреждениях (26,2\%).

И, наконец, третий вариант выбора образует совокупность респондентов, однозначно ориентированных на ценности демократии и на этом основании отрицающих институт сити-менеджмента в качестве антидемократичного, лишающего население их права придавать руководителю муниципального образования легитимность посредством законно определенной процедуры выборов. Третья позиция была удостоена наименьшего внимания со стороны респондентов - $23 \%$.

\section{Сопряженность между оценкой качества работы сити-менеджеров и правовым порядком вступления его в должность, в \%}

\begin{tabular}{|c|c|c|c|}
\hline \multirow[b]{2}{*}{$\begin{array}{c}\text { Оценка качества } \\
\text { работы } \\
\text { сити-менеджеров } \\
\text { населением }\end{array}$} & \multicolumn{3}{|c|}{$\begin{array}{c}\text { Правовой порядок вступления в должность } \\
\text { главы муниципального образования }\end{array}$} \\
\hline & $\begin{array}{c}\text { Отмену выборов при- } \\
\text { му только положитель- } \\
\text { но, часто выборы- } \\
\text { это отмывание денег } \\
\text { или механизм получе- } \\
\text { ния привилегий и не- } \\
\text { прикосновенности } \\
(29,7) \\
\end{array}$ & \begin{tabular}{|c|} 
Я устал от политики и \\
приму главу муници- \\
палитета в любом ка- \\
честве, если он будет \\
успешно решать соци- \\
ально-экономические \\
проблемы \\
$(47,3)$ \\
\end{tabular} & $\begin{array}{l}\text { Отмену выборов мэра } \\
\text { оцениваю крайне не- } \\
\text { гативно, т.к. для меня } \\
\text { демократические при- } \\
\text { нципы имеют боль- } \\
\text { шое значение } \\
\qquad(23,0) \\
\end{array}$ \\
\hline $\begin{array}{l}\text { Да, качество жизни на- } \\
\text { селения улучшилось }\end{array}$ & 60,9 & 31,5 & 7,6 \\
\hline $\begin{array}{l}\text { Нет, сити-менеджеры } \\
\text { показали себя безот- } \\
\text { ветственными и не- } \\
\text { профессиональными } \\
\text { руководителями }\end{array}$ & 14,4 & 44,3 & 41,3 \\
\hline $\begin{array}{l}\text { Смена принципов } \\
\text { вступления в долж- } \\
\text { ность руководителя } \\
\text { муниципального об- } \\
\text { разования никак не } \\
\text { повлияла на качество } \\
\text { жизни населения } \\
\end{array}$ & 21,5 & 59,3 & 19,2 \\
\hline
\end{tabular}


На неё чаще всего ориентировались студенты $(33,6 \%)$ и служащие в негосударственных учреждениях $(39,2 \%)$.

Результаты получились в определенной степени ожидаемыми. Правда, мы не можем сказать, что выборы мэров во всех крупных городах Ростовской области и раньше не вызывали интереса у населения. Ещё до наступления эпохи сити-менеджмента на последних выборах мэра в Ростове-на-Дону была явка 51,81\% избирателей [5], в Таганроге - 63,32\% [6], в Каменске-Шахтинском $53,59 \%$ [7]. На этом фоне значительно хуже выглядит ситуация с явкой на избирательные участки на последних выборах мэра в Батайске 8 сентября 2013 года - 36,53\% [8], а также в двух попавших в нашу выборку городах Адыгеи: 26 мая 2013 года в Майкопе - 27\% [9] и 15 сентября 2014 года в Адыгейске $28,8 \%$ [10]. Как видим, ситуацию с активностью избирателей на муниципальных выборах можно охарактеризовать в качестве неоднозначной, поэтому за годы, которые миновали с момента отмены процедуры прямых выборов руководителей муниципальных образований, мы можем фиксировать падение интереса со стороны населения муниципалитетов к практике избрания мэров. Отчасти это может быть связано с тем, что муниципальные сообщества просто смирились с новым способом вступления глав местной власти в должность, но в основе своей, по нашему мнению, ситуацию следует интерпретировать иначе. Для наглядного пояснения представим результаты опроса, сведенные в табл. 10.

В табл. 10 показано сопряжение данных из таблицы 6. В ней видно, что имеет место существенное изменение в распределении результатов оценок правового порядка вступления в должность руководителя муниципального образования в зависимости от того, как участник опроса оценивает качество работы городского управляющего. Рассмотрим это на примере первой строки. Так, если в общем массиве выборки отмену выборов мэра положительно оценили только 29,7\%, то в группе, где был выбран вариант «да, качество жизни населения улучшилось», положительная оценка дана от 60,9\% респондентов. Остальные два варианта ответов, наоборот, снизили свои значения: в группе «я устал от политики и приму главу муниципалитета в любом качестве, если он будет успешно решать социальноэкономические проблемы» с 47,3\% (общая выборка) до $31,5 \%$, а в группе «отмену выборов мэра оцениваю крайне негативно, т.к. для меня демократические принципы имеют большое значение» с 23,0\% (общая выборка) до 7,6\%. Такая же логика распределения значений имеется во второй и третьей строках.

Таким образом, мы видим четкую динамику ичифр положительного, нейтрального или отрицательного отношения к сити-менеджменту, напрямую связанную с положительнылм, нейтральным или отрицательнылм отночением к качеству их профессиональной деятельности. Следовательно, можно предположить, что снижение интереса $\kappa$ возрождению института выборных мэров находится в прямой зависимости от повышения качества жизни населения муниципалитетов.

Заключение. Проведенный социологический опрос был направлен на изучение четырёх основных аспектов, связанных с установлением общественной состоятельности института сити-менеджмента в муниципальных образованиях Ростовской области и Республики Адыгея: доверие к реформе, цели реформы, удовлетворенность от реформы и ожидание последствий от реформы. По всем заявленным позициям с определенной степенью допущений можно выделить три группы в виде 1) сторонников реформы и 2) её противников, каждая из которых насчитывает от четверти до трети от числа опрошенных, а также 3) не определившееся большинство, согласное на любую управленческую модель, лишь бы она привела к повышению уровня социально-экономического развития территорий. Среди респондентов преобладают мотивы недоверия к реформе, вызывающие вопросы о целесообразности её проведения. Одна треть опрошенного населения расходится с законодателем в определении целей реформы, видя в ней исключительно политическую направленность, а другая треть вообще не усматривает в ней никаких целей. Чуть больше четверти респондентов удовлетворены результатами реформы, менее трети дает им отрицательную оценку, немногим более сорока процентов не увидели для себя никаких результатов. Практически все опрошен- 
ные по тому или иному аспекту опасаются, что за реформу придется заплатить высокую цену, указывая на возможность наступления потенциально опасных рисков управленческого и социально-экономического характера. Наименее значимыми оказываются риски политического характера, т.к. однозначно негативное суждение об отмене муниципальных выборов высказало меньше четверти из числа опрошенных.

Делая вывод об общественной состоятельности института сити-менеджмента в муниципальных образованиях Ростовской области и Республики Адыгея, очень важно обратить внимание на то, что её достижение находится в прямой зависимости от качества реформы. Этот вывод делается на основе выявления ряда корреляционных зависимостей между степенью удовлетворенностью работой сити-менеджеров, оценкой их профессионализма, с одной стороны, и отношением к целевым характеристикам реформы с другой. В отличие от научного сообщества, среди которого доминирует упрощенное отношение к институту сити-менеджмента как достройке властной вертикали, в обществе преобладает более дифференцированное его восприятие, в структуре которого есть в том числе и представление о сити-менеджменте как замене политических отношений на хозяйственно-экономические. Очень важно в связи с этим в работе муниципальных властей избегать имитационных форм деятельности, увлекаться жонглированием показателями социально-экономического развития, а также иными подобными акциями, которые способны подорвать доверие не только к реформе, но и к власти, её инициирующей.

\section{Литература}

1. Сахранов В.Р. Институт сити-менеджмента: проблема соотношения легитимности и эффективности / Ars administrandi: искусство власти и управления // Под ред. Д. С. Будановой. - Иваново, 2019.

2. Великая Н. М. Трансформация местного самоуправления в малых и средних городах глазами экспертного сообщества // Вопросы политологии. - 2019. - Т. 9. - №6.

3. Медовый В. В. Особенности социальноэкономического развития регионов на совре- менном этапе // Актуальные проблемы экономики, социологии и права. - 2017. - №1.

4. Горская А.Н. Перспективы советно-управленческой формы организации городского управления в России // Современный город: власть, экономика, управление. - 2015. - Т. 1.

5. Постановление муниципальной избирательной комиссии города Ростова-на-Дону от 15 марта 2010 г. №25-1 «О результатах выбора Мэра города Ростова-на-Дону 14 марта 2010 года» [Электронный ресурс]. - Режим доступа: https://www.ростов-избирком.pф/ single-post/2010/03/15/Результаты-выборовМэра-города-РостованаДону.

6. В прошедшее воскресенье, 4 марта 2012 года состоялись выборы Президента Российской Федерации, мэра города Таганрога и дополнительные выборы депутатов Городской Думы города Таганрога по 9-му и 20му избирательным округам. Беzформата. Таганрог [Электронный ресурс]. — Режим доступа: http://taganrog.bezformata.com/listnews/ taganroga-i-dopolnitelnie-vibori/3201920.

7. Досрочные выборы мэра города Каменск-Шахтинский 14.03.2010. Leftfront.org. Информационно-справочная система ЛФВыборы [Электронный ресурс]. — Режим доступа: https://www.leftfront.org/elections/ election.php? ID=16876.

8. Выборы мэра города Батайска в Ростовской области 08.09.2013. Leftfront.org. Информационно-справочная система ЛФ-Выборы [Электронный ресурс]. — Режим доступа: https://www.leftfront.org/elections/election. php? ID=47093.

9. Кандидат от «ЕДИНОЙ РОССИИ» победил на выборах мэра Майкопа. Беzформата. Майкоп [Электронный ресурс]. - Режим доступа: http://maikop.bezformata.com/listnews/ pobedil-na-viborah-mera-majkopa/11763857/.

10. Действующий мэр города Адыгейска набрал более $70 \%$ голосов. Новости ИА REGNUM [Электронный ресурс]. - Режим доступа: https://regnum.ru/news/polit/1847561. html.

\section{References}

1. Sahranov V.R. Institut siti-menedzhmenta: problema sootnoshenija legitimnosti i jeffektivnosti [Institute of city management: the problem of the ratio of legitimacy and efficiency] / 
Ars administrandi: iskusstvo vlasti i upravlenija [Ars administrandi: the art of power and management] // In D. S. Budanova (ed.). - Ivanovo, 2019.

2. Velikaja N.M. Transformacija mestnogo samoupravlenija v malyh i srednih gorodah glazami jekspertnogo soobshhestva [Transformation of local self-government in small and medium-sized cities through the eyes of the expert community] // Voprosy politologii [Questions of political science]. - 2019. — Vol. 9. — №6.

3. Medovyj V.V. Osobennosti social'nojekonomicheskogo razvitija regionov na sovremennom jetape [Features of socio-economic development of regions at the present stage] // Aktual'nye problemy jekonomiki, sociologii i prava [Actual problems of Economics, sociology and law]. — 2017. — №1.

4. Gorskaja A.N. Perspektivy sovetno-upravlencheskoj formy organizacii gorodskogo upravlenija v Rossii [Prospects of the Sovietmanagerial form of organization of urban management in Russia] // Sovremennyj gorod: vlast', jekonomika, upravlenie [Modern city: power, economy, management]. - 2015. - Vol. 1.

5. Postanovlenie municipal'noj izbiratel'noj komissii goroda Rostova-na-Donu ot 15 marta 2010 g. №25-1 «O rezul'tatah vybora Mjera goroda Rostova-na-Donu 14 marta 2010 goda» [Resolution of the municipal election Commission of the city of Rostov-on-Don dated March 15, 2010 №25-1 «On the results of the selection of the Mayor of the city of Rostov-on-Don on March 14, 2010»] [Jelektronnyj resurs]. URL: https://www.rostov-izbirkom.rf/singlepost/2010/03/15/Результаты-выборов-Мэрагорода-РостованаДону.

6. V proshedshee voskresen'e, 4 marta 2012 goda sostojalis' vybory Prezidenta Rossijskoj Federacii, mjera goroda Taganroga i dopolnitel'nye vybory deputatov Gorodskoj Dumy goroda Taganroga po 9-mu i 20-mu izbiratel'nym okrugam [Last Sunday, March 4, 2012, elections of the President of the Russian Federation, the mayor of Taganrog and additional elections of deputies of the city Duma of Taganrog for the 9th and 20th electoral districts were held]. Bezformata. Taganrog [Jelektronnyj resurs]. - URL: http://taganrog.bezformata.com/listnews/taganroga-i-dopolnitelnievibori/3201920.

7. Dosrochnye vybory mjera goroda Kamensk-Shahtinskij 14.03.2010 [Early elections of the mayor of Kamensk-Shakhtinsky 14.03.2010]. Leftfront.org. Informacionnospravochnaja sistema LF-Vybory [Information and reference system LF-Vybory] [Jelektronnyj resurs]. — URL: https://www.leftfront.org/elections/election.php? ID=16876.

8. Vybory mjera goroda Batajska v Rostovskoj oblasti 08.09.2013 [Election of the mayor of Bataysk in the Rostov region 08.09.2013]. Leftfront.org. Informacionno-spravochnaja sistema LF-Vybory [Information and reference system LF-Vybory] [Jelektronnyj resurs]. — URL: https://www.leftfront.org/elections/election. php? ID $=47093$.

9. Kandidat ot «EDINOJ ROSSII» pobedil na vyborah mjera Majkopa [The Candidate from UNITED RUSSIA won the mayoral election in Maykop]. Bezformata. Maikop [Jelektronnyj resurs]. - URL: http://maikop.bezformata. com/listnews/pobedil-na-viborah-mera-majko$\mathrm{pa} / 11763857 /$.

10. Dejstvujushhij mjer goroda Adygejska nabral bolee $70 \%$ golosov. Novosti IA REGNUM [The Current mayor of Adygeisk received more than $70 \%$ of the vote. News of IA REGNUM] [Jelektronnyj resurs]. — URL: https:// regnum.ru/news/polit/1847561.html. 


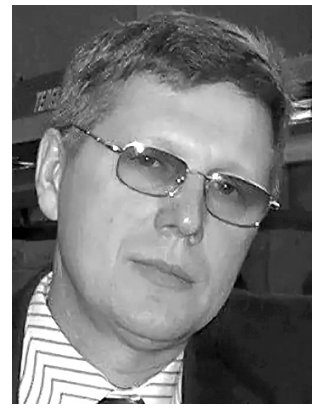

Дятлов Александр Викторович - доктор социологических наук, профессор Института социологии и регионоведения Южного федерального университета.

Dyatlov Alexander Viktorovich - Doctor of Sociological Sciences, Professor, Institute of Sociology and Regional Studies, Southern Federal University.

346500, г. Ростов-на-Дону, ул. Пушкинская, 160 160 Pushkinskaya st., 346500, Rostov-on-Don, Russia

E-mail: avdyatlov@yandex.ru

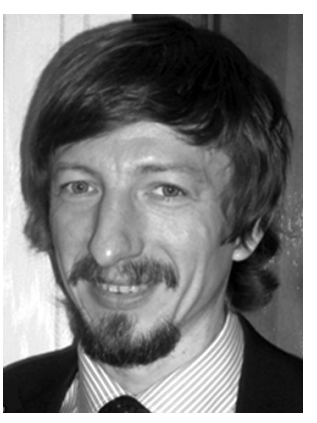

Ковалев Виталий Владимирович - доктор социологических наук, профессор Института социологии и регионоведения Южного федерального университета.

Kovalev Vitaliy Vladimirovich - Doctor of Sociological Sciences, Professor, Institute of Sociology and Regional Studies, Southern Federal University.

346500, г. Ростов-на-Дону, ул. Пушкинская, 160

160 Pushkinskaya st., 346500, Rostov-on-Don, Russia

E-mail: vitkovalev71@gmail.com 